Final version published as: Angus, L., Watson, J.C., Elliott, R., Schneider, K., \& Timulak, L. (2015). Humanistic psychotherapy research 1990-2015: From methodological innovation to evidence-supported treatment outcomes and beyond. Psychotherapy Research, 25, 330-347.

DOI: 10.1080/10503307.2014.989290 . This is an author final version (October 13, 2014) and may not exactly replicate the final version. It is not the copy of record.

\title{
Humanistic Psychotherapy Research 1990-2015: From methodological innovation to evidence-supported treatment outcomes and beyond
}

\author{
Lynne Angus, Ph.D., York University, Toronto, Canada \\ Jeanne Watson, Ph.D., OISE, University of Toronto, Toronto, Canada \\ Robert Elliott, Ph.D., University of Strathclyde, Glasgow, Scotland
}

Kirk Schneider, Ph.D., Adjunct Faculty, Saybrook University, Teachers College, Columbia University, California Institute of Integral Studies, USA

Ladislav Timuluk, Ph.D., School of Psychology, Trinity College, Dublin, Ireland.

Prepared for the 25th anniversary of Psychotherapy Research.

\begin{abstract}
Over the past twenty five years, humanistic psychotherapy (HP) researchers have actively contributed to the development and implementation of innovative practice-informed research measures and coding systems. Qualitative and quantitative research findings, including metaanalyses, support the identification of HP approaches as evidence-based treatments for a variety of psychological conditions. Implications for future psychotherapy research, training and practice are discussed in terms of addressing the persistent disjunction between significant HP research productivity and relatively low support for HP approaches in university-based clinical training programs, funding agencies and government-supported clinical guidelines. Finally, specific recommendations are provided to further enhance and expand the impact of humanistic psychotherapy research for clinical training programs and the development of treatment guidelines.
\end{abstract}




\section{Humanistic Psychotherapy Research 1990-2015: From methodological innovation to evidence-supported treatment outcomes and beyond}

Arising out of the nineteenth century romantic movement and existentialist and phenomenological philosophy, modern humanistic psychology addresses two basic questions: "What does it mean to be fully human?"; and "How does that understanding illuminate the vital or fulfilled life?" (Schneider, Pierson, \& Bugental, 2015, p. xvii). Schneider and Leitner (2002) suggest that humanistic psychotherapy addresses the conditions by which people can come to intimately know themselves and each other, and, to the extent possible, fulfill their aspirations. As evidenced in the psychotherapy research literature, a diverse range of humanistic therapy (HP) approaches and research methods have emerged over the past quarter century to further understand and address clients' problems in living. The purpose of this paper is to provide an overview/update of developments in humanistic psychotherapy research (HPR) from 1990-2015, in honor of the twenty-fifth anniversary of Psychotherapy Research, and to reflect on future directions, challenges and opportunities for humanistic psychotherapy research in the $21^{\text {st }}$ century.

Accordingly, we first provide a brief historical overview of the development of HP treatment approaches, principles of practice and research methods that also addresses research, practice and training challenges currently faced by HP practitioners and researchers. Next we provide a summary of humanistic therapy research contributions to the field of psychotherapy research, over the past quarter century, that summarizes HP meta-analytic outcome findings and recent qualitative and process-outcome studies investigating key mechanisms of client change in humanistic therapy approaches. Finally, we critically review significant humanistic psychotherapy research findings in the context of recent developments in psychotherapy training, research, and practice as a whole and discuss key opportunities and challenges facing HP practitioners and researchers over the next quarter century.

\section{Humanistic psychotherapy research and practice: A brief overview}

While it is difficult to do justice to the complexity and breadth encompassed by a humanistic approach to psychological research and practice, we offer the following working definition of humanistic psychotherapy for the purposes of the present paper: "Humanism is concerned with such existential themes as meaning, mortality, freedom, limitation, values, creativity, and spirituality as these arise in personal, interpersonal, social, and cultural contexts. In psychotherapy, humanism places special emphasis on the personal, interpersonal, and contextual dimensions of therapy and on clients' reflections on their relationship with self, others, and the larger psychosocial world" (Schneider \& Langle, 2012, p. 428). Accordingly, humanistic therapies are part of the main tradition of humanistic psychology and include client/person-centred (Rogers, 1961), constructivist (Neimeyer \& Mahoney, 1995), emotion-focused (EFT, also known as process-experiential; Greenberg, Rice \& Elliott, 1993), existential meaningmaking (Schneider \& Krug, 2010; Yalom, 1980), focusing-oriented (Gendlin, 1978); Gestalt (Perls, Hefferline \& Goodman, 1951), and transpersonal (Wilber, Engler \& Brown, 1986) psychotherapies.

Despite the fact that these humanistic psychotherapy (HP) approaches vary to some degree in technique and conception, Elliott, Watson, Greenberg, Timulak and Freire (2013) argue that contemporary HP approaches share a distinctive set of theoretical assumptions and principles of HP practice. They include: 
Humanistic Psychotherapy Research 1990-2015

a) Endorsement of the centrality of a genuinely empathic and prizing therapeutic relationship as the most important theoretical underpinning of humanistic therapy. As such, each client's subjective experience is of central importance, and, in an effort to grasp that experience, the humanistic therapist attempts to enter empathically into the client's world in a way that provides the client with a new, emotionally validating interpersonal experience.

b) Focus on the promotion of in-therapy client experiencing, defined as the holistic process of immediate, ongoing awareness that includes perceiving, sensing, feeling, thinking, and wanting/intending. As such, therapist interventions and responses that deepen or stimulate client emotional experiencing are embedded within the context of an empathic facilitative relationship. Clients are viewed as meaning-creating, symbolizing agents, whose subjective experience is an essential aspect of their humanity.

c) Emphasis on the operation of an integrative, formative tendency, oriented toward survival, growth, personal agency, and the creation of meaning. Internal tacit experiencing is seen as an important guide to conscious adaptive experience, and potentially available to awareness when the client turns attention internally within the context of a supportive therapeutic relationship.

d) Consistently person-centered when engaging clients. This involves genuine therapist concern and respect for each client who is seen holistically, as a unique individual, who possesses a complex array of emotions, behaviors, stories and capacities that can, at times, be viewed as representative of a particular clinical diagnostic category, but never reduced to one (Elliott et al., 2013; p. 495-496).

It is important to point out that some of these HP assumptions and practices clash with what Wampold (2008) has termed an 'excruciatingly narrow' consensus on what is scientific and should contribute to $20^{\text {th }}$ - and $21^{\text {st }}$-century social science research. Critically, this includes group designs, unidimensional measurement, and emphasis on the statistical central tendency, all of which ignore the person of the client and therapist and their unique contributions to treatment outcomes. There is also a focus on objective, impersonal measurement, away from lived experience and relationally-based knowing; reliance on simplistic linear, one-way mechanistic causal models, as opposed to complex nonlinear self-organizing processes; and an emphasis on dysfunction rather than growth. Thus, until the 1980's, humanistic therapy researchers did not have a set of research methods appropriate to their worldview and practices. All of these issues raised the question of whether humanistic therapy research was even possible.

In spite of the inherent contradictions, humanistic therapy researchers using traditional, positivistic methods have been able to establish strong empirical support for the contributions of the therapeutic relationship for facilitating client change processes in HP, which has led to a growing recognition of the importance of a productive therapeutic alliance, across a diverse range of therapeutic approaches. For instance, therapists' empathy and responsivity to client feedback have been highlighted in recent approaches to behavioral (Bunting \& Hayes, 2008), psychoanalytic (Stolorow, 2011), cognitive-behavioral (Kertes, Westra, Angus \& Marcus, 2011; Westra, 2012) and multicultural psychotherapy (Comas-Diaz, 2012). This shift represents a revival of the core assumptions of humanistic psychotherapy that rose to prominence in the 1960's as a counterweight to more prescriptive therapy models of treatment. The incorporation of more humanistic principles of practice has been fuelled by systematic research advances in the investigation of key processes of change, particularly in HP treatment approaches. 
The evolution of HP research methods and practices can be traced to the seminal contributions of key researchers, as documented in Castonguay and associates' work Bringing Psychotherapy Research to Life (2010), which presents the work of several key figures that contributed to the development of HPs such as Carl Rogers, Irene Elkin, Allen Bergin, Eugene Gendlin, Laura Rice, Donald Kiesler, Michael Lambert, Clara Hill, Robert Elliott, William Stiles and Les Greenberg. Beginning with Carl Rogers (1957), an illustrious line of humanistic psychotherapy researchers, most of whom were also clinical practitioners, have created a distinct tradition of methods and methodologies within the larger discipline of psychotherapy research, that have in turn, contributed to the evolution of psychotherapy practice.

Historically, humanistic psychotherapy research has been characterized by a distinct set of four recurrent interests, which have collectively moved away from positivism and toward a human science approach more consistent with core humanistic therapy values: close analysis of psychotherapy process, client experience, qualitative methods, systematic case studies and change processes. On the more positivist end of the spectrum has been the close analysis of psychotherapy process, introduced by HP researchers with an initial focus on the differences between good and poor outcome cases (Gendlin, 1978), the quality of therapist facilitative behavior (Truax \& Carkhuff, 1967), client experiencing (Klein, Mathieu-Coughlan \& Kiesler, 1986), and therapist /client vocal quality (Rice \& Sapiera, 1984).

Over the past 25 years, this HP research tradition has expanded to include specific process variables such as client expressed emotional arousal (Warwar \& Greenberg, 1999); emotional processing (Watson \& Prosser, 2007); expressed empathy (Watson, 2007); and client narrative integration (Boritz, Bryntwick, Angus, Greenberg \& Constantino, 2014), innovative moments (Gonçalves, Mendes, Ribeiro, Angus \& Greenberg, 2010) and reflective processing (Watson, Steckley \& McMullen, 2014). Additionally, discourse style and verbal response modes evidenced in humanistic therapeutic sessions have been examined in the work of Stiles (1979), Hill (1978) and Sachse (1992). This growing list of innovations has significantly contributed to the development of change process research as a distinct focus of psychotherapy research in the last twenty-five years.

Moreover this intensive analysis of psychotherapy sessions has informed theory and practice leading to the development of focusing-oriented psychotherapy as well as emotionfocused psychotherapy (Greenberg \& Watson, 1998; Goldman, Greenberg \& Angus, 2006). Both of these approaches initially emerged from an enhanced understanding of HP therapeutic practices based on close observation of therapeutic processes. Technological advances have supported this work, as illustrated by Rogers' use of phonograph, and later wire recordings of therapy sessions in the 1940's. More recently, audio and video technology have made it possible to review, observe and empirically analyze client and therapist performances for the rich, qualitative description of moment to moment therapeutic interactions, as they unfold within therapy sessions (Boritz et al., 2014).

Over time, these interests have taken humanistic therapy researchers to the edges of the prevailing positivism and its associated quantitative methods, and beyond, into phenomenological/existential and constructivist philosophies of science and their associated qualitative, mixed, and reflexive methods. As evidenced in the following review of humanistic therapy research findings, and addressed more fully in the final discussion, the development of client-focused inquiry methods and mixed qualitative-quantitative methods, in particular, have had a significant impact on a resurgence of qualitative, quantitative and process-outcome humanistic therapy research studies, over the past twenty-five years. 
At the same time, it is also important to note that despite both a renewed practice, and a proliferation of HP research methods and empirical studies (as evidenced in the research review to follow), there has also been a paradoxical decline in humanistic training programs (Heatherington, Messer, Angus, Strauman, Friedlander \& Kolden, 2012), over the past twentyfive years. As noted by Levy and Anderson (2013), the powerful forward march of Cognitive Behavioral Psychotherapy (CBT), and its promotion as an empirically-supported treatment approach, has resulted in both a rapid expansion of CBT identified training programs and a concomitant decline in humanistic, psychodynamic and interpersonal therapy training clinics, across North America. This trend has occurred despite increasing empirical evidence that supports the identification of a range of research-supported psychotherapy approaches, especially for depression (see APA Division 12 Research-supported Treatments website).

It is our hope that the following comprehensive review of significant HP research results will contribute to an increased recognition of efficacious HP treatments in the psychotherapy practice field and support the future development of mental health treatment policies/guidelines and expanded humanistic training opportunities over the next quarter century. First, we review empirical studies that have investigated the efficacy of HP treatment approaches, and in effect ask the question, 'do HPs work?' Next, we pose the key research question of 'how do HPs work?', and report research findings emerging from HP process-outcome studies investigating humanistic principles of practice and qualitative inquiries addressing the firsthand perspective of HP clients.

\section{Quantitative Humanistic Psychotherapy Research}

Are Humanistic Psychotherapies Efficacious?

Quantitative outcome research is the most positivistic of the different threads of HP research, and has generally been undertaken as political necessity. Since the founding of Psychotherapy Research, research on the outcome of humanistic psychotherapies has increased many times over, from 37 studies, reviewed by Greenberg, Elliott \& Lietaer (1994) in the first meta-analysis of this literature, to many more than the 191 studies included in the most recent meta-analysis (Elliott et al., 2013). These meta-analyses consistently and with increasing strength and differentiation support the following conclusions:

1. Humanistic psychotherapies are associated with large pre-post client change. Using a 2008 sample, Elliott et al. (2013) looked at 199 samples of clients, from 191 studies, involving 14,235 clients, and reported a large weighted pre-post effect size of .93 (95\% CI: .85 to 1.01). Furthermore, this is particularly true for general symptom measures, as indicated by two large UK-based studies (Stiles, Barkham, Twigg, Mellor-Clark \& Cooper, 2006; Stiles, Barkham, Mellor-Clark \& Connell, 2008).

2. Clients' large post therapy gains are maintained over early \& late follow-ups. Following therapy, Elliott et al. (2013) found that clients in humanistic psychotherapies maintained and slightly improved their gains -- pre-to-follow-up change at less than 12 months was 1.05; while at a year or more it was 1.11. The maintenance of gains post-therapy is consistent with humanistic ideas about clients' self-determination and empowerment, suggesting that clients continue to develop on their own after they have left therapy.

3. Clients in humanistic psychotherapies show large gains relative to clients who receive no therapy. Elliott et al. (2013) analyzed data from 62 controlled studies, 31 of these RCTs (ns = 2,144 in humanistic psychotherapies vs. 1,958 in wait-list or no-therapy conditions). They found a controlled weighted effect size of .76 (CI: .64 to .88); with randomization making no 
difference, except that the confidence interval was slightly wider. These findings provide strong support that humanistic psychotherapies are useful and effective treatments for clients.

4. Humanistic psychotherapies in general are clinically and statistically equivalent to other therapies. In 100 studies (91 of them RCTs; $n=6,097$ clients), there was virtually no difference between humanistic and other therapies in amount of pre-post change (weighted comparative effect size $=.01$; CI: -.05 to .07 ); again, results were virtually identical regardless of whether studies were randomized or not.

5. So-called nondirective-supportive therapies (NDSTs) have worse outcomes than CBT. Elliott et al. (2013) found that treatments labelled by researchers as "supportive" or "nondirective" have somewhat smaller amounts of pre-post change than CBT (37 studies; weighted effect size $=-.27$; CI : -.41 to -.13 ). In general, these treatments turned out to be watered-down, non bona fide versions of humanistic therapies, used by CBT researchers.

6. Person-centred therapy is as effective, and emotion-focused therapy (EFT) might be more effective than CBT. Person-centred therapy was equivalent to CBT (22 studies; weighted effect size: -.06; CI: -.11 to -.01). In a small number of studies, emotion-focused therapies for individuals or couples appeared to be more effective when compared to CBT (6 studies; weighted comparative effect size $=.53$; CI: .13 to .93 ).

7. Humanistic therapies are most effective for interpersonal/relational problems trauma. For a range of interpersonal or relational problems, Elliott et al. (2013) found very large pre-post and controlled effects, as well as significantly better comparative effects for humanistic therapies. EFT for couples has long been recognized as an evidence-based treatment (EBT) for couples (Chambless et al., 1998); however, a range of individual humanistic therapies appear to meet criteria as EBTs for interpersonal difficulties including the treatment of trauma from childhood abuse (but not necessarily PTSD, where there is still almost no research).

8. Humanistic therapies meet criteria as evidence-based treatments for depression. For depression in general, humanistic therapies have been extensively researched, to the point where the claim of empirical support as efficacious and specific (i.e., superior to a placebo or active treatment) can be supported in general, based on meta-analytic data, with EFT for moderate depression and person-centered therapy for perinatal depression having the most solid evidence (Elliott et al., 2013).

9. For psychotic conditions, humanistic therapies appear to meet criteria as evidencebased treatments. Although based on a relatively small number of studies, the evidence analyzed by Elliott et al. (2013) showed large pre-post effects and superior comparative treatment effects (6 studies; +.39; CI: .10 to .68), suggesting that humanistic therapies may be effective with clients experiencing psychotic processes (e.g., schizophrenia).

10. Humanistic therapies have promise for helping people cope with chronic medical conditions and for reducing habitual self-damaging activities. Coping with difficult medical or physical conditions (e.g., cancer) and habitual self-damaging activities (e.g., substance misuse) present challenges for most forms of therapy. However, Elliott et al (2013) found that for both of these client populations, humanistic therapies were in general associated with moderate prepost improvement, were superior to no treatment controls, and were equivalent to other approaches (most commonly CBT).

11. For anxiety difficulties, the humanistic therapies studied so far appear to be less effective than $C B T$. For anxiety problems (especially panic and generalized anxiety), Elliott et al. (2013) reported large pre-post effects, moderate controlled effects, but consistently poorer results when compared to CBT. Although researcher allegiance effects are a factor, Elliott et al. 
Humanistic Psychotherapy Research 1990-2015

(2013) argued that more work is required to develop more effective process-guiding approaches, as indicated by evidence now emerging from ongoing research (Timulak \& McElvaney, 2012). At this point, however, based on the available evidence, the use of traditional humanistic therapies can only be justified as second line treatments for clients who have also tried or refused CBT.

\section{Qualitative Humanistic Psychotherapy Research}

\section{How Does Humanistic Psychotherapy Work?}

Given the central importance of the person of the client in humanistic therapeutic approaches (Tallman \& Bohart,1999), it is perhaps not surprising that humanistic researchers have been at the forefront, of not only developing, but implementing qualitative research designs (Elliott, 2002; McLeod, 2011; Watson, Goldman \& Greenberg, 2007; Wertz,2002), and posttherapy interview inquiries (Elliott, 1986; Hardtke \& Angus, 2004; Angus \& Kagan, 2013), to capture clients' experiences of change in a range of humanistic psychotherapy approaches.

By the early 1990's, two key methods had emerged that contributed to the development of a qualitative approach to the study of client experiences in humanistic therapy. First, Interpersonal Process Recall procedures (IPR; Kagan, 1984) were used to capture clients' accounts of moment-to-moment experiencing in therapy sessions (Elliott, 1986), while Grounded Theory (Glaser \& Strauss, 1967) and Empirical Phenomenology (Fessler, 1978; Giorgi, 1975) provided rigorous, systematic methodological frameworks for the qualitative analysis of clients' interview transcripts. This innovative integration of qualitative research methods resulted in a new line of innovative HP studies of clients' immediate experiences in therapy sessions and significant therapy events. Later, Hill and colleagues further adapted Grounded Theory to develop Consensual Qualitative Research (CQR; Hill, 2012; Hill, Thompson \& Williams, 1997) for the analysis of clients' first person accounts address a range of client experiences and therapy events ( Hill, Knox \& Hess, 2012). These methods are highly consistent with humanistic assumptions about the importance of the person, lived experience and relational knowing.

Studies of clients' experience of humanistic therapy. An important contribution to the investigation of clients' experiences in psychotherapy can be found in the work of David Rennie (1992, 1994a, 1994b) who showed that clients engaged in monitoring their therapists during therapy sessions, and generally preferred to defer to their therapist's plans and shortcomings rather than challenge them. Rennie's approach to qualitative inquiry informed Watson and Rennie's (1994) study on clients' experience of systematic evocative unfolding of clients' problematic reactions in emotion-focused therapy sessions, as well as Angus and Rennie's (1988; 1989) focus on clients' metaphoric expressions, and Moerman and McLeod's (2006) investigation of clients with an alcohol-related problem. Additionally, Knox (2008) has studied clients' perceptions of moments of relational depth, Schnellbacher and Leijssen (2009) and Rodgers (2002) studied clients' perceptions of helpful/important in-session processes, and Meyers (2000) studied clients' perceptions of empathy. Overall, these studies underscore the central importance of the relational qualities offered by humanistic therapists, as clients consistently identified therapists' empathic skills as essential for fostering new awareness of emotions and enhanced self-understanding.

Studies of helpful and hindering events. Qualitative research on humanistic psychotherapy has also focused on the most helpful or hindering client-identified events in HP therapy sessions (Balmforth \& Elliott, 2012; Elliott, 1985; Grafanaki \& McLeod, 1999; 2002; Holowaty \& Paivio, 2012; Timulak, Belicova, \& Miler, 2010; Timulak \& Elliott, 2003; Timulak 
\& Lietaer, 2001). To date, these studies have highlighted the importance of a) building clients' sense of safety in therapy; b) recognizing the fragility of clients' sense of safety in the therapeutic process; c) highlighting how clients are active participants in important changes in therapy (e.g., through taking risks in self-disclosing, through pursuing emotionally painful issues); d) showing how the therapist's relational and emotional processing skills can help the client to bear emotional pain, experience flow, relief, new awareness, and self-reflection, and e) establishing new, coherent, self-narratives and self-empowerment.

Intensive single case studies. Many published qualitative research studies investigating humanistic psychotherapy approaches have employed intensive case study research methods (McLeod, 2010). For instance, Watson et al.(2007) conducted a series of intensive process analyses of good and poor outcome clients undergoing emotion-focused treatment for depression. Findings highlighted the importance of the quality of clients' emotional and narrative processing, the presence of positive introjects at the beginning of therapy, and the presence of social support and the capacity to build a strong therapeutic alliance, in contributing to positive therapeutic outcomes in short-term psychotherapy for depression. Humanistic researchers (Brinegar, Salvi, \& Stiles, 2008; Honos-Webb, Stiles, Greenberg, \& Goldman, 1998; HonosWebb, Surko, Stiles, \& Greenberg, 1999; Osatuke, Glick, Stiles, Shapiro, \& Barkham, 2005) have also drawn on Stiles' (2002) Assimilation of Problematic Experiences (APES) framework to study EFT and person-centered therapies of depression. Research findings have shown that clients with more advanced assimilation of problematic issues recover from depression and were better able to recognize and assert their needs in their therapy sessions.

Elliott and his research group have conducted intensive case studies looking at causal links between emotion-focused/humanistic therapy processes and therapy outcome for a range of disorders such as social anxiety, panic and bipolar disorder (Elliott, 2002; MacLeod \& Elliott, 2012; MacLeod, Elliott, Rodgers, 2012; Stephens, Elliott, \& MacLeod, 2011; Stinckens \& Elliott, 2014). Intensive case analyses also have been employed to develop a theory of emotional transformation (McNally, Timulak, \& Greenberg, 2014), resolution of self-critical processes (Stinckens, Lietaer \& Leijssen, 2002) and successful resolution of health anxiety (Smith, Shoemark, McLeod, \& McLeod, 2014) in the context of humanistic therapy treatments. Taken as a whole, findings indicate that, in addition to depression (Elliott et al., 2013), humanistic psychotherapy approaches such as emotion-focused therapy can initiate healing processes for a range of clinical disorders for which group outcome evidence of treatment effectiveness has yet to be established.

Finally, a recent series of intensive case studies (Angus \& Kagan, 2013; Angus \& Hardtke, 2007; Cunha, Gonçalves, Hill, Mendes, Ribeiro, Sousa, Angus, \& Greenberg, 2012; Gonçalves, Mendes, Cruz, Ribeiro, Sousa, Angus \& Greenberg, 2012; Mendes, Ribeiro, Angus, Greenberg, Sousa, \& Gonçalves, 2010; 2011) have drawn on the York I Depression study transcript dataset (Angus, 2012) to examine emotion-focused and client-centred humanistic therapy sessions from a narrative-informed perspective on therapy change processes (Angus \& McLeod, 2004). Findings from these studies have highlighted the importance of protest moments (such as challenging the voice of self-criticism), reclamation of own needs (for instance by setting a boundary in an abusive relationship), working with client ambivalence and selfnarrative reconstruction in good outcome therapy sessions.

Meta-synthesis of qualitative outcomes. Timulak and Creaner (2010) point out that qualitative studies to date have not only captured clients' experiences in humanistic psychotherapy but have also assessed the impact that humanistic treatments have had on their 
lives. As such, these studies are well-suited for assessing spontaneously reported changes by clients that may address a broader range of therapy outcomes not captured by standardized questionnaires. To explore this question, Timulak and Creaner (2010) conducted a metasynthesis of eight qualitative research studies addressing clients' experiences of change in humanistic psychotherapy, identifying 11 meta-categories of client-reported change: Healthier Emotional Experiencing, Experiences of Appreciating Vulnerability, Experiences of SelfCompassion, Resilience, Empowerment, Mastery of Symptoms, Enjoyment of Changed Life Circumstances, Feeling Supported, Enjoyment of Interpersonal Encounters, Self-insight/Self awareness and Changed View of Others.

Results of the meta-synthesis indicated that humanistic clients identified qualities such as a greater awareness of emotional experiencing and heightened vulnerability as important, positive outcomes of their humanistic therapy treatments, outcomes rarely assessed in the context of standardized therapy outcome measures. Levitt, Stanley, Frankl and Raina (2005) suggest that psychotherapy researchers who only include standardized symptom distress measures to evaluate humanistic treatment outcomes, and do not include client first person accounts of therapeutic change, are 'using thermometers to weigh oranges'. As such, psychotherapy researchers are well advised to include post-therapy qualitative interviews (Elliott, 2010; Angus \& Kagan, 2013), in addition to standardized symptom measures, as part of their evaluation of humanistic therapy outcomes.

Although qualitative methods are still a relatively recent development in psychotherapy research, it is clear that they have gained increasing acceptance by HP researchers over the past 25 years. Frommer and Rennie (2002) suggest, however, that in terms of the important criterion of publication, especially in psychology's mainstream journals, qualitative research is still on the margin. To this end, several authors have suggested that there is a need to develop explicit standards and criteria for the assessment and review of qualitative psychotherapy research in a wider range of psychotherapy-based, peer-review journals (Elliott, Fischer, \& Rennie, 1999; McLeod, 2013).

\section{Process-Outcome Humanistic Psychotherapy Research}

As noted by Elliott (2010), humanistic psychotherapy researchers have been distinctive in their focus on change processes within and across HP treatments. Indeed, many innovative genres of HP change process research have emerged over the last quarter century to enrich our clinical understanding of how change happens in effective HP treatments, including helpful aspects of therapy post session inquiry (Elliott \& James, 1989); comprehensive process analysis (Elliott, 1989); conversational analysis (Muntigl, White, Watkins, Horvath \& Angus, 2013; Sutherland, Peräkylä, \& Elliott, 2014); process-outcome quantitative and qualitative research investigations (Angus, Goldman \& Mergenthaler 2008; Cooper, Watson, Hoelldampf, 2010), measure development (Wiggins, Elliott \& Cooper, 2012), and systematic case studies (McLeod, 2010; Angus \& Kagan, 2013). In particular, humanistic therapy researchers have investigated three key mechanisms of change that cohere closely with HP practice principles (Elliott et al., 2013): focus on the development of productive therapeutic relationship, therapist empathy, heightened client experiencing and emotional/experiential engagement in therapy sessions.

The therapeutic relationship. Since Rogers' (1957) identification of therapists' empathy, nonjudgmental acceptance, warmth, and congruence, as necessary and sufficient conditions for therapeutic change, accumulated research evidence points to a moderate but consistent relationship between the therapeutic conditions and outcome (Elliott et al., 2013; 
Elliott, Bohart, Watson \& Greenberg, 2011; Farber \& Doolin, 2011; Horvath, Del Re, Flückiger \& Symonds, 2011; Kolden, Klein, Wang, \& Austin, 2011; Watson, 2001). The Task Force on the therapeutic relationship designated therapist empathy as "demonstrably effective"; positive regard as "probably effective"; and congruence and genuineness as "promising but insufficient research to judge" (Norcross \& Wampold, 2011, p. 424).

Examining the conceptual overlap between the construct of the therapeutic alliance and the therapeutic conditions, Watson and Geller (2005) found that the Working Alliance Inventory (WAI) (Horvath \& Greenberg, 1986) and Barrett- Lennard Relationship Inventory (BLRI) (Barrett-Lennard, 1962) were highly correlated while therapeutic alliance (WAI) mediated the relationship between the relationship conditions (BLRI) and outcome in both EFT and CBT for depression. Intriguingly, this finding held despite the fact that CBT therapists were found to be more didactic in their therapy sessions while EFT therapists were more supportive in their interactions with clients.

Therapist empathy. Investigating the impact of therapist empathy on changes in clients' internal working models of self and other, Watson et al. (2014) found that therapists' empathy was associated with significant improvement in attachment insecurity and significant decreases in self-criticism, neglectful, and controlling behaviors towards the self at the end of therapy and in turn, these positive changes were significantly associated with good outcome in brief humanistic treatments of depression. Watson and Prosser (2007) also found that changes in clients' affect regulation mediated the impact of therapists' empathy on outcome, while Toukmanian and colleagues showed that therapists' empathy, attunement, and exploration were each associated with higher levels of client experiencing and client perceptual processing (Gordon \& Toukmanian, 2002). Therapist empathy, however, was best predicted by therapists' attunement (Macaulay, Toukmanian \& Gordon, 2007). These recent studies provide additional evidence and support for the important role that the therapist empathic attunement and communication skills contribute to promoting positive outcomes in psychotherapy.

Quality of client exploration of inner experiencing. Research on clients' experiencing continues to be an important focus of inquiry by humanistic psychotherapy researchers. Goldman, Greenberg, and Pos (2005) found that positive shifts in the quality of clients' exploration of their inner experience -- as measured by the Client Experiencing Scale (Klein, Mathieu, Gendlin \& Kiesler, 1969) -- was a stronger predictor of outcome than the working alliance in client-centered and emotion-focused psychotherapy for depression. Previous studies have also addressed the impact of therapist proposals on the depth of clients' self-exploration (Sachse, 1992; Sachse \& Maus, 1991; Sachse \& Elliott, 2002; Sachse \& Takens, 2004) in therapy sessions and found that therapists' statements that were high in experiencing resulted in higher levels of clients' experiencing during therapy sessions and that the depth of therapist experiential focus predicted overall outcome (Adams \& Greenberg, 1996).

Qualities of clients' experiencing promoted in humanistic psychotherapy approaches , such as a focus on inner experiencing, questioning and reflection on experience leading to shifts in perception, feeling, or thinking, have also been consistently related to good outcome across a range of therapeutic approaches, including CBT and psychodynamic therapy (Elliott, Greenberg \& Lietaer, 2004, 2012; Hendricks, 2002; Giyaur, Sharf \& Hilsenroth, 2005; Godfrey, Chalder, Risdale, Seed \& Ogden, 2007; Leahy, 2002; Watson \& Bedard, 2006). These findings provide support for the humanistic view that the manner in which clients' process their experience in therapy is core to change, irrespective of treatment approach. 
Quality of clients' emotional engagement. Research studies have also shown that higher expressed emotional arousal at mid-treatment, increased reflection on aroused emotion (Warwar \& Greenberg, 2000) and deeper emotional processing late in therapy (Pos, Greenberg, Goldman \& Korman, 2003), predict good outcome in EFT and CCT treatments of depression. In another study using the same dataset, Pos, Greenberg and Warwar (2010) found that after controlling for both the alliance and client emotional processing at the beginning of therapy, the quality of clients' experiencing during the working phase of treatment was the best predictor of outcome.

In terms of frequency and intensity of emotional expression, Carryer and Greenberg (2010) have shown that a medium rate $(25 \%)$ of moderate to high intensity emotional expression was evidenced in good outcome EFT, suggesting that finding an optimal ratio of emotional expression to emotional intensity is important for effective therapy outcomes. Greenberg, Auszra and Herrmann (2007) have reported that mid-phase emotional productivity predicted $66 \%$ of the outcome variance, over and above working alliance, in EFT for depression and suggest that productive processing of emotion may be one of the best predictors of outcome. Extending this line of inquiry, Watson, McMullen, Prosser, and Bedard (2011) found that clients' level of affect regulation at the end of therapy mediated the relationship between client level of emotional processing in therapy and final outcome, independent of the working alliance.

Quality of narrative process and emotion integration. Angus and colleagues have also investigated the contributions of narrative processes and emotional expression in CCT and EFT treatments of depression (Angus, Levitt \& Hardtke, 1999; Angus, Lewin, Bouffard \& Rotondi-Trevisan, 2004; Angus, 2012). For instance, Lewin, Angus \& Blagov (2003) found that therapists in good outcome EFT cases were twice as likely to help clients shift to emotionfocused and reflexive narrative modes than therapists of clients with poor outcome. Lewin and Angus (2008) subsequently established that higher frequencies of emotion-focused and reflexivemeaning making shifts predicted higher experiencing levels and treatment outcomes in emotionfocused therapy of depression. More recently, using multi-level modeling analyses, Boritz, Angus, Monette, Hollis-Walker, and Warwar (2011) have established that clients in CCT and EFT treatments of depression evidence a significant increase in the specificity of personal stories, from early to late phase therapy sessions, while recovery from depression was only predicted by a combination of high narrative specificity and expressed arousal in late phase sessions. Results were interpreted as supporting the importance of narrative and emotion integration in effective HP treatments of depression.

Performance models. Finally, there has been a growing research interest in understanding the contributions of humanistic process-guiding approaches - such as tasks in emotion-focused therapies (Greenberg et al.,1993) - to effective treatment outcomes. In practice, process-guiding humanistic therapy approaches strive to maintain a creative tension between the person-centered emphasis on creating a genuinely empathic and prizing therapeutic relationship, and a task-focused style of engagement that promotes deeper client experiencing and consequent meaning creation in therapy sessions.

In order to investigate the relationship between in-session client processes and productive treatment outcomes humanistic/emotion-focused psychotherapy researchers have employed task analytic methodology (Greenberg, 1983) to identify and test within session performance models -that more fully describe client behaviors, and therapist interventions, during specific change episodes. In particular, intensive analyses of two-chair and empty chair dialogue tasks in EFT and Gestalt psychotherapy has led to the development of performance models that specify and 
empirically validate key components necessary for task resolution (Greenberg, 1979, 1983; Greenberg \& Webster, 1982; Greenberg \& Foerster, 1996; Greenberg \& Malcolm, 2002; Sicoli \& Halberg, 1998; Whelton \& Greenberg, 2000).

Two-chair dialogues have been shown to be effective in resolving negative treatment of self, for example self-criticism, self-silencing, and self-neglect (Shahar, Carlin, Engle, Hedge, Szepsenwol \& Arkowitz, 2011), and depression (Watson, Gordon, Stermac, Kalogerakos \& Steckley, 2003). In turn, empty chair dialogues have been used to effectively address complex trauma (Paivio \& Greenberg, 1995; Paivio \& Pascual-Leone, 2010) and unresolved relationship issues (Greenberg \& Malcolm, 2002; Greenberg, Warwar \& Malcolm, 2008). Paivio, Holowaty and Hall (2004) found that complex trauma clients who engaged in empty chair dialogues evidenced more pre-post change than those who did not, independent of the therapeutic alliance.

More recently, Meneses and Greenberg (2011) tested a model of interpersonal forgiveness in the context of Emotion-focused therapy for couples and found three key steps, a) acceptance of responsibility for causing the emotional injury, b) the expression of shame or empathic distress and c) the expression of a heart-felt apology - contributed to a resolution of emotional injuries, irrespective of initial degree of marital distress. Finally, employing task analytic methodology, Pascual-Leone and Greenberg (2007) showed that in emotionally productive EFT sessions, clients move from a state of global distress through fear, shame, and aggressive anger to the expression of needs and negative self-evaluations; followed by assertive anger, self-soothing, hurt, and grief, indicative of more advanced processing.

\section{Discussion \\ Key contributions of HP research findings: 1990-2015}

Despite a challenging funding environment and significant decline in HP clinical training centres over the past twenty-five years, HP researchers have completed an increasing range of randomized controlled trials to assess the efficacy of HP approaches. These studies have included randomized comparisons among combinations of emotion-focused therapy, clientcentred and cognitive behaviour therapy to address specific clinical disorders such as depression (Ellison, Greenberg, Goldman \& Angus, 2009; Greenberg \& Watson, 1998; Goldman, Greenberg \& Angus, 2006; Watson et al., 2003) and Complex Trauma (Paivio et al., 2004). Importantly, to answer the key empirical question of 'does HP work?', recent meta-analytic analyses, based on findings from 191 HP outcome studies (Elliott et al., 2013), have established that HP's are associated with large pre-post client change at treatment termination, up to 18month follow-up and, in general, are clinically and statistically equivalent to other therapies, including CBT.

Additionally, the implementation of multi-level modeling analyses for the identification of key client-therapist process variables, in the context of HP RCT research trials, has placed HP researchers at the forefront of identifying core mechanisms of change that are consistent with HP clinical practice principles and contribute to clinically significant outcomes in HP treatments. Specifically, recent process-outcome findings have established that therapist empathy, clients' emotional productivity, experiencing, and manner of personal narrative disclosures significantly contribute to positive HP treatment, providing convergent validity for key HP theoretical assumptions and practice principles (Elliott et al., 2013). From this work, we conclude that humanistic psychotherapy researchers have made significant contributions to innovative advancements in the field of psychotherapy methods, measures and research findings, over the past 25 years. 
HP qualitative research findings have also provided a strong empirical base for the further development of humanistic psychotherapy theory and practice. Specifically, there has been increasing recognition of the role of developmental processes (Watson, 2011) and narrative expression (Angus \& Greenberg, 2011) for enhanced emotion regulation as well as a refined understanding of case formulation (Goldman \& Greenberg, 1997; Watson, Goldman \& Greenberg, 2007) in EFT treatments. This evolution of theory has further supported recent efforts to conceptualize how EFT can be further applied to social anxiety, generalized anxiety disorder, and eating disorders.

Finally, it is clear that there has been a renewed emphasis on the importance of the therapeutic attitudes as key ingredients of change with empathy seen as multifunctional as it contributes to clients' capacities for affect regulation and the development of positive introjects and ways of treating affective and emotional experience (Watson et al., 2014; Watson et al., 2011). The impact of research on practice is a continually iterative process with changes in practice leading to new research questions and methods of analysis.

\section{Implications for Humanistic Psychotherapy Research, Practice and Training.}

While the primary impetus for this review has been to investigate the empirical status of humanistic therapy for a diverse and growing constituency of psychotherapy researchers and practitioners, a further inspiration was to assess the present implications of humanistic therapy research for the expansion of HP clinical graduate training and the optimization of effective psychotherapy practice as a whole. Acknowledging that theoretical and research questions still remain to be addressed, we draw the following conclusions about the current state of psychotherapy research and theory in humanistic practice: (1) the renewal of key humanistic practice principles such as therapist empathy and the role of the relationship conditions are foundational elements of therapeutic effectiveness and endorsement of those principles is a salient and growing phenomenon evidenced in leading specialty areas of psychotherapy; 2) HP treatments meet criteria as evidence-based treatments for depression, interpersonal difficulties, and coping with psychosis, self-damaging behaviors and chronic medical conditions and should therefore be included in the development of clinical practice guidelines; 3) HP researchers have been at the forefront of developing methodologically pluralistic research approaches - such as qualitative data collection and analysis methods and innovative measures of therapy process and outcome - to address clinically rich, practice-informed research questions in ways that are much more consistent with humanistic values; (4) qualitative and process-outcomes studies have further differentiated and enriched our understanding of HP principles of practice as they relate to clients' experiences of change; and finally (5) HP research findings provide strong empirical support for the inclusion of humanistic practice principles as a core dimension of HP training and provide significant support for an expansion of HP training clinics and programs. To elaborate further, we will identify five central themes that have emerged from our overview.

A first major observation addresses the empirical status of HP therapies as evidencesupported treatments for specific clinical disorders. Based on their HP meta-analytic findings established by Elliott et al., (2013), and summarized in this paper, we conclude that humanistic psychotherapies are supported by multiple lines of scientific evidence and should therefore be included in clinical-guidelines and lists of evidence-based psychotherapy.

A second major observation is that HP researchers are currently at the forefront of using mixed methods to address clinically rich, practice-informed research questions in the context of HP RCT's. For instance, humanistic researchers such as Robert Elliott, Jeanne Watson, Sandra Paivio, Antonio Pascual-Leone, Alberta Pos and Lynne Angus have increasingly employed 
qualitative and mixed methods approaches to study therapeutic processes and outcomes demonstrating the capacity to empirically investigate process variables relevant to HP practice principles - such as expressed emotion, empathy, client experiencing levels and personal story disclosure - in the context of achieving clinically significant change in humanistic treatments of depression, anxiety and complex trauma.

A third major observation is that the current state of humanistic qualitative and processoutcome therapy research evidence indicates convincingly that in terms of HP therapy practice:

(a) The authentic personal relationship is fundamental to effective practice.

(b) Clients' emotional pain is rendered more bearable within the context of an attuned and understanding therapeutic relationship.

(c) The collaborative nature of the therapeutic relationship is key to the process of therapy unfolding and to the disclosure of clients' narratives and personal stories in order to develop a shared understanding and interpersonal trust.

(d) The essential connection between humanistic therapy research activity and practice innovation evidenced in our current review of the HP research literature is consistent with the early contributions of Rogers, Gendlin, and Klein, all of whom viewed psychotherapy research and practice as an integral part of their commitment to the development of a distinct humanistic psychotherapy model and treatment approach. Recognition of the contribution of key humanistic principles of practice - including Rogers' (1959) theory of facilitative conditions, Bugental (1987) and May's (1983) theories of therapeutic presence, Friedman (1985) and Yalom's (1980) theories of interpersonal engagement, and views of experiential contact variously put forward by Mahrer (1996), Perls (1976), Gendlin (1978), Greenberg (Greenberg \& Van Bulen 1998) - have received increasing support from a growing constituency of psychotherapy practitioners, researchers and theorists (Elliot et al., 2013; Schneider \& Längle, 2012). F

Furthermore, a "third generation" of integrative cognitive-behavioral treatment approaches, such as mindfulness-based cognitive therapy (Segal, Williams, \& Teasdale, 2001), motivational interviewing-informed CBT for severe anxiety (Westra, 2012), acceptance and commitment therapy (Hayes, Strosahl, \& Wilson, 1999), existentially informed CBT for generalized anxiety (Wolfe, 2008) and compassion-focused therapy (Gilbert, 2009) appear to have much in common with humanistic process-guiding practice models and research approaches (Elliott et al., 2013).

Finally, a fifth major observation addresses the perplexing contradiction between the weight of specific HP research evidence, as summarized in this article, and the present state of official professional advocacy in relation to the development of clinical practice guidelines, policy directives and HP training programs. Although the contributors to this article, as well as other recent overviews (Schneider \& Längle, 2012), report converging research findings that emphatically affirm the value of humanistic practice principles, as well as the efficacy of HP treatment outcomes, large segments of the public, the media, and even the professional practice community continue to privilege a CBT treatment model that minimizes the important contributions of therapist and client factors (Baker, McFall, \& Shoham, 2009; Elkins, 2009) as well as the contributions of other research-supported treatment approaches.

Moreover, this reluctance to recognize the contributions of humanistic practice principles to productive treatment outcomes not only neglects a wealth of therapy effectiveness literature (Elkins, 2012; Wampold, 2012), but it also presents disturbing implications for the optimization of therapeutic training and practice as a whole (Heatherington et al.,2012; Längle \& Kriz, 2012; Schneider \& DuPlock, 2012; Stolorow, 2012). If there is one message that resounds through the 
chorus of contributions to this article, it is that humanistic practice principles of empathy, alliance, receptivity to client feedback, emotional deepening, and meaning making are critical to therapeutic healing in HP treatment approaches as well as others.

To this end we argue that there is converging evidence to suggest that therapeutic training should emphasize the person of the therapist (Duncan, 2010; Fauth, Gates, Vinca, \& Boles, 2007; Geller \& Greenberg, 2012) and enhance the development of empathic communication skills, the capacity to enhance clients' emotional expression and self-regulation, and the capacity to develop a secure and productive therapeutic alliance for the facilitation of client narrative disclosure and productive meaning making in therapy sessions.

As noted earlier, Heatherington et al. (2012) used cross-sectional data from a recent survey of North American faculty theoretical orientations within clinical programs, and found a significantly higher endorsement of cognitive-behavioral orientation as compared with those from behavioral, psychodynamic, humanistic, and family systems orientations. In order to investigate changes in the predominance of theoretical orientation in training programs over time, Levy and Anderson (2013) analyzed longitudinal data on psychotherapy theoretical orientations (PTO) for North American clinical psychology faculty members over two decades. Results demonstrated that clinical psychology has moved from a field that was relatively balanced in percentages of faculty from cognitive-behavioural (CBT), psychodynamic, humanistic, behavioural, and family PTOs to one that has shown highly significant linear growth for one single PTO: CBT. Most other PTOs, and in particular humanistic therapy orientation, showed a significant linear decline. Levy and Anderson (2013) caution that even if important research findings from other PTOs, such as the benefits of a strong working alliance and therapist empathy are now co-opted into CBT, essential aspects of these HP clinical concepts and interventions are at risk of being stripped down, muddied, or lost in a conflation with CBT treatment principles when they are not guided and informed by bona fide Humanistic training principles and expertise, acquired in the context of University-based HP clinics and training programs (Pierson, Krug, Sharp, \& Piwowarski, 2015).

On the basis of the current HP research review, we suggest that HP clinicians and researchers are under-represented in the context of University-based Clinical Psychology and Counseling training programs and insufficiently represented on government-mandated bodies charged with developing clinical practice policies and guidelines. Given the substantive empirical research evidence, humanistic therapy training should be included in university-based clinical and counselling training programs, so that the significant decline of humanistic therapy training programs, over the past 20 years, can be reversed.

\section{The Next 25 Years: Recommendations and Future Steps}

Prediction is a matter of either extrapolating present linear trends or else projecting our hopes and fears forward into an unknown, nonlinear future. In the case of humanistic psychotherapy research, we have been discussing two opposing trends: On one hand, there is the hopeful but nascent revival and resurgence of innovative humanistic approaches to psychology and psychotherapy, including a rapidly developing evidence base; and on the other hand, there is the powerful forward march of CBT toward hegemony.

Under such conditions, some HP researchers may become discouraged or tempted to fall back on a fundamentalist position, rejecting quantitative research as tainted by positivism while endorsing the sole benefits of qualitative research strategies and single case analyses. In this article, we have tried to highlight the significant research contributions of both qualitative and 
quantitative HP research findings for wide dissemination to clinical practitioners, researchers and mental health policy makers. As such, we have emphasized the important contributions of qualitative and process-outcomes studies on HP that have enriched our understanding of how HPs work; we have also summarized HP outcome research findings that have identified HP approaches have shown to be efficacious with specific client concerns. Building on this work, we encourage future HP researchers to undertake controlled studies of increasing scale, in order to continue to provide evidence that will impact treatment guidelines.

While research evidence is necessary, it may not be sufficient to make a real impact on treatment guidelines, as professional self-interests often have a significant political influence on the development of policy initiatives. As such, we will also need to engage in strategic thinking and planning regarding future steps: alliance-building, networking, lobbying, and persistence over time. First, HP therapy researchers will need to help build coalitions within their approach, overcoming whatever internal divisions have been holding back further development and the presentation of a united front. In the UK, for example, the new humanistic "counselling for depression" model (Sanders \& Hill, 2014) has integrated person-centered and EFT approaches to create a growing training, accreditation, and research initiative.

Second, because of the broader developments we have been describing, HP researchers and practitioners increasingly have shared interests with colleagues from psychodynamic and systemic traditions, as well as mental health service user groups. Thus, it is important for HPs to overcome their traditionally individualistic and apolitical stance in order to build bridges with a range of potential allies. As suggested earlier, it may be the case that each of the major therapeutic orientations - cognitive-behavioral, psychoanalytic, existential-humanistic, and multicultural -- can be optimized when they draw on HP practice principles and interventions; humanistic psychotherapy could also benefit from the selective implementation of effective intervention practices representative of other bona fide therapy orientations.

Third, because of their shared commitment to empirical research, HP researchers are in a particularly good position to connect with sympathetic CBT researchers, particularly those from the acceptance-based, third wave approaches that have incorporated humanistic ideas into their treatments, as noted above. In fact, we would like to see a continuing place for all the main approaches in the further development of theory and research on psychotherapy. For example, we think that Psychotherapy Research over the past 25 years has suffered from an underrepresentation of research from the CBT tradition and even more importantly from research in which researchers from different theoretical traditions come together to collaborate and dialogue.

Finally, as Elliott et al. (2013) have argued, there are strong scientific reasons (for example, on the basis of the Bayesian model of inference) for HP researchers to lobby for meaningful representation on the scientific grant review panels and groups who are developing mental health treatment guidelines in various countries, pushing for full consideration of a wide range of evidence and a fair and balanced reading of that evidence. Thus, we invite a more strategic, activist and constructive stance with regard to mental health treatment guideline development on the part of organizations like the Society for Psychotherapy Research, the new German Association for Humanistic Psychotherapies, and the Society for Humanistic Psychology (in the US and Canada). Supporting and engaging with each other in these ways will lead to greater understanding of psychotherapy, a highly focused relational form of healing that is essential to the well-being of individuals and societies. Our clients deserve our full commitment to work together to improve treatment outcomes and provide them with a range of choices to facilitate their growth and healing. 


\section{References}

Adams, K. E., \& Greenberg, L.S. (1996). Therapists' influence on depressed clients' therapeutic experiencing and outcome. Paper presented at the 43rd Annual convention of the Society for Psychotherapeutic Research, St. Amelia, FL.

Angus, L. (2012). An integrative understanding of narrative and emotion processes in Emotionfocused therapy of depression: Implications for theory, research and practice. Psychotherapy Research, 22, 4, 367-380.

Angus, L. \& Greenberg, L. (2011). Working with narrative in Emotion-focused Therapy: Changing stories, healing lives. Washington D.C.: American Psychological Association.

Angus, L., Goldman, R. \& Mergenthaler, E. (2008). Introduction to Special Section. One case, multiple measures: An intensive case-analytic approach to understanding client change processes in evidence-based, emotion-focused therapy of depression. Psychotherapy Research, 18, 6, 629-634.

Angus, L. \& Hardtke, K. (2007). Insight and story change in brief experiential therapy for depression: An intensive narrative process analysis. In Castonguay, L. and Hill, C., Insight and Psychotherapy (pp187-207). Washington D.C.: APA Press.

Angus, L. \& Kagan, F. (2013). Self-narrative reconstruction in Emotion-focused Therapy of depression: An intensive, single case analysis. Psychotherapy: Theory, Research and Practice, 50, 4, 525-534.

Angus, L. E., Lewin, J., Bouffard, B., \& Rotondi-Trevisan, D. (2004). "What's the story?" working with narrative in experiential psychotherapy. In Angus, L. E., \& McLeod, J. (Eds.), The Handbook of Narrative and Psychotherapy: Practice, Theory and Research (pp.87-101). Thousand Oaks, CA: Sage Publications.

Angus, L., Levitt, H, \& Hardtke, K. (1999). The narrative processes coding system: Research applications and implications for psychotherapeutic practice. Journal of Clinical Psychology, 55, 1255-1270.

Angus, L. \& McLeod, J. (2004). The Handbook of Narrative and Psychotherapy : Practice, theory and research. Thousand Oaks, CA: Sage Publications

Angus, L. \& Rennie, D. (1989). Envisioning the representational world: Metaphoric expression in psychotherapy relationships. Psychotherapy, Fall, 26, 372-379.

Angus, L. \& Rennie, D. (1988). Therapist participation in metaphor generation: Collaborative and non-collaborative styles. Psychotherapy, Winter, 25, 552-560.

Baker, T. B., McFall, R. M., \& Shoham, V. (2009). Current status and future prospects of clinical psychology: Toward a scientifically principled approach to mental and behavioral health care. Psychological Science in the Public Interest, 9, 67-103.

Balmforth, J., \& Elliott, R. (2012). 'I never talked about, ever': A comprehensive process analysis of a significant client disclosure event in therapy. Counselling and Psychotherapy Research, 12, 2-12.

Barrett-Lennard, G. T. (1962). Dimensions of therapist response as causal factors in therapeutic change. Psychological Monographs, 76, (43, Whole No. 562).

Boritz, T., Angus, L., Monette, G., Hollis-Walker, L. \& Warwar, S. (2011). Narrative and emotion integration in psychotherapy: Investigating the relationship between autobiographical memory specificity and expressed emotional arousal in brief Emotionfocused and Client-centred treatments of depression. Psychotherapy Research, 21, 1, 1626.

Boritz, T., Bryntwick, E., Angus, L., Constantino, M. \& Greenberg, L. (2014) . Narrative and 
emotion in psychotherapy: An empirical test of the Narrative-Emotion Process Coding System. Psychotherapy Research, 24, 5, 594-607.

Brinegar, M. G., Salvi, L. M., \& Stiles, W. B. (2008). The case of Lisa and the assimilation model: The interrelatedness of problematic voices. Psychotherapy Research, 18, 657-66.

Bugental, J. (1987). The art of the psychotherapist. New York: Norton.

Bunting, K., \& Hayes, S. (2008). Language and meaning: Acceptance and commitment therapy and the EI model. In K. J. Schneider (Ed.), Existential-integrative psychotherapy: Guideposts to the core of practice (pp. 217-234). New York: Routledge.

Carryer, J. R., \& Greenberg, L. S. (2010). Optimal levels of emotional arousal in experiential therapy of depression. Journal of Consulting and Clinical Psychology, 78, 190-199.

Castonguay, L.G., Muran, J.C., Angus, L., Hayes, J.A., Ladany, N., \& Anderson, T. (Eds.) (2010), Bringing psychotherapy research to life: Understanding change through the work of leading clinical researchers. Washington, DC: APA.

Chambless, D.L, Baker, M.J., Baucom, D.H., Beutler, L.E., Calhoun, K.S., Crits-Christoph, P., Daiuto, A., DeRubeis, R., Detweiler, J., Haaga, D.A.F., Johnson, S.B., McCurry, S., Mueser, K.T., Pope, K.S., Sanderson, W.C., Shoham, V., Stickle, T., Williams, D.A., \& Woody, S.R. (1998). Update on Empirically Validated Therapies, II. The Clinical Psychologist, 51(1), 3-16.

Comas-Diaz, L. (2012). Humanism and multiculturalism: An evolutionary alliance. Psychotherapy, 49, 437-441.

Cooper, M., Watson, J.C., \& Hölldampf, D. (Eds.), Person-Centred and Experiential Therapies Work: A review of the research on counselling, psychotherapy and related practices. Ross-on-Wye, UK: PCCS Books.

Cunha, C., Gonçalves, M. M., Hill, C. E., Mendes, I., Ribeiro, A. P., Sousa, I., Angus, L. \& Greenberg, L. S. (2012). Therapist interventions and client innovative moments in emotion-focused therapy for depression. Psychotherapy, 49, 536-548.

Duncan, B. L. (2010). On becoming a better therapist. Washington, DC: American Psychological Association.

Elkins, D. N. (2009). Humanistic psychology: A clinical manifesto: A critique of clinical psychology and the need for progressive alternatives. Colorado Springs, CO: University of the Rockies Press.

Elkins, D. N. (2012). Toward a common focus in psychotherapy research. Psychotherapy, 49, 450-454.

Elliott, R. (1985). Helpful and non-helpful events in brief counseling interviews: An empirical taxonomy. Journal of Counseling Psychology, 32, 307-322.

Elliott, R. (1986). Interpersonal Process Recall (IPR) as a psychotherapy process research method. In L. Greenberg \& W. Pinsof (Eds.), The psychotherapeutic process (pp. 503527). New York: Guilford Press.

Elliott, R. (1989). Comprehensive Process Analysis: Understanding the change process in significant therapy events. In M. Packer \& R.B. Addison (Eds.), Entering the circle: Hermeneutic investigation in psychology (pp. 165-184). Albany, NY: SUNY Press.

Elliott, R. (2002). Hermeneutic single case efficacy design. Psychotherapy Research, 12, 1-20.

Elliott, R. (2010). Psychotherapy change process research: Realizing the promise. Psychotherapy Research, 20, 123-135. 
Elliott, R., Bohart, A.C., Watson, J.C., \& Greenberg, L.S. (2011). Empathy. In J. Norcross (Ed.), Psychotherapy relationships that work (2nd ed.) (pp. 132-152). New York: Oxford University Press.

Elliott, R., Fischer, C.T. \& Rennie, D.L. (1999). Evolving guidelines for publication of qualitative research studies in psychology and related fields. British Journal of Clinical Psychology, 38, 215-229.

Elliott, R., Greenberg, L.S., \& Lietaer, G. (2004). Research on experiential psychotherapies. In M.J. Lambert (Ed.), Bergin \& Garfield's Handbook of psychotherapy and behaviour change (5th Ed., pp. 493-540). New York: Wiley.

Elliott, R. \& James, E. (1989). Varieties of client experience in psychotherapy: An analysis of the literature. Clinical Psychology Review, 9, 443-467.

Elliott, R., Watson, J., Greenberg, L.S., Timulak, L., \& Freire, E. (2013). Research on humanistic-experiential psychotherapies. In M.J. Lambert (Ed.), Bergin \& Garfield's Handbook of psychotherapy and behavior change (6th ed.) (pp. 495-538). New York: Wiley.

Ellison, J., Greenberg, L., Goldman, R. \& Angus, L. (2009). Maintenance of gains at follow-up in experiential therapies for depression. Journal of Consulting and Clinical Psychology, Vol. 77 (1), 103-112.

Ellison, J., Greenberg, L., Goldman, R. \& Angus, L. (2009). Maintenance of gains at follow-up in experiential therapies for depression. Journal of Consulting and Clinical Psychology. Vol. 77 (1), 103-112.

Farber, B.A., \& Doolin, E.M. (2011). Positive regard and affirmation. In J. Norcross (Ed.), Psychotherapy relationships that work (2nd Ed.) (pp. 168-186). New York: Oxford University Press.

Fauth, J., Gates, S., Vinca, M. A., \& Boles, S. (2007). Big ideas for psychotherapy training. Psychotherapy: Theory, Research, Practice, Training, 44, 384-391.

Fessler, R. (1978). A phenomenological investigation of psychotherapeutic interpretation. Dissertation Abstracts International, Vol. 39, 6 B, 2981-2982.

Friedman, M. (1985). The healing dialogue in psychotherapy. Northvale, NJ: Jason Aronson.

Fromm, E. (1965). Escape from freedom. New York: Avon.

Frommer, J., \& Rennie, D. (2002). Qualitative Psychotherapy Research: Methods and Methodology. Psychotherapy Research, 12(2), 241-242.

Geller, S. M., \& Greenberg, L. S. (2012). Therapeutic presence: A mindful approach to effective therapy. Washington, DC: American Psychological Association.

Gendlin, E. (1978). Focusing. New York: Bantam.

Gilbert, P. (2009). The compassionate mind. London: Constable \& Robinson.

Giorgi, A. (1975). An application of phenomenological method in psychology. In A. Giorgi, C. Fischer \& E. Murray (Eds.), Duquesne Studies in Phenomenological Psychology: Vol. 2. (pp. 83-103). Pittsburgh, PA: Duquesne University Press.

Giyaur, K., Sharf, J., \& Hilsenroth, M. J. (2005). The capacity for dynamic process scale (CDPS) and patient engagement in opiate addiction treatment. Journal of Nervous and Mental Disease, 193(12), 833-838.

Glaser, B. G. \& Strauss, A. (1967). The discovery of grounded theory: Strategies for qualitative research. Chicago: Aldine.

Godfrey, E., Chalder, T., Risdale, L., Seed, P. \& Ogden, J. (2007). Investigating the active ingredients of cognitive behavioural therapy and counselling for patients with chronic 
fatigue syndrome: Developing a new process measure to assess treatment fidelity and predict outcome. British Journal of Clinical Psychology, 46, 253-272.

Goldman, R. \& Greenberg, L. (1997). Case formulation in experiential therapy. In T. Ells' Handbook of Psychotherapy Case Formulation. (pp. 402-429). New York: Guilford.

Goldman, R.N., Greenberg, L.S., \& Angus, L. (2006). The effects of adding emotion-focused interventions to the client-centered relationship conditions in the treatment of depression. Psychotherapy Research, 16, 537-549.

Goldman, R.N., Greenberg, L.S., \& Pos, A.E. (2005). Depth of emotional experience and outcome. Psychotherapy Research, 15, 248-260.

Gonçalves, M., Mendes, I., Ribeiro, A., Angus, L. \& Greenberg, L. (2010). Innovative moments and change in Emotion-focused Therapy: The case of Lisa. Journal of Constructivist Psychology, 23, 267-294.

Gonçalves, M., Mendes, I., Cruz, C., Ribeiro, A., Sousa, I., Angus, L. \& Greenberg, L. (2012). Innovative moments and change in Client-centred psychotherapy. Psychotherapy Research, 22, 4, 389-401.

Gordon, K. M., \& Toukmanian, S. G. (2002). Is how it is said important? The association between quality of therapist interventions and client processing. Counselling \& Psychotherapy Research, 2, 88-98.

Grafanaki, S. \& McLeod, J. (1999). Narrative processes in the construction of helpful and hindering events in experiential psychotherapy. Psychotherapy Research, 9, 289-303.

Grafanaki, S., \& McLeod, J. (2002). Experiential congruence: Qualitative analysis of client and counselor narrative accounts of significant events in time-limited person-centred therapy. Counselling and Psychotherapy Research, 2, 20-32.

Greenberg, L.S. (1979). Resolving splits: The two-chair technique. Psychotherapy: Theory, Research and Practice, 16, 310-318.

Greenberg, L. S. (1983). Toward a task analysis of conflict resolution in Gestalt Therapy. Psychotherapy: Theory, Research and Practice, 20, 190-201.

Greenberg, L. S., Auszra, L., \& Herrmann, I. R. (2007). The relationship among emotional productivity, emotional arousal and outcome in experiential therapy of depression. Psychotherapy Research, 17, 482-493.

Greenberg, L., Elliott, R., \& Lietaer, G. (1994). Research on experiential psychotherapies. In A. E. Bergin \& S. L. Garfield (Eds.) Handbook of psychotherapy and behavior change (4th Ed., pp. 509-539). New York: Wiley.

Greenberg, L. S. \& Foerster, F. (1996). Resolving unfinished business: The process of change. Journal of Consulting and Clinical Psychology, 64, 439-446.

Greenberg, L.S. \& Malcolm, W. (2002). Resolving unfinished business: Relating process to outcome. Journal of Consulting and Clinical Psychology, 70, 406-416.

Greenberg, L. S., Rice, L. N. \& Elliott, R. (1993). Facilitating emotional change: The momentby-moment process. New York. N.Y.: Guilford Press.

Greenberg, L. \& Van Balen, R. (1998). The theory of experience-centered therapies. In L.S. Greenberg, J. C. Watson, \& G. Lietaer (Eds.), Handbook of experiential psychotherapy (pp. 28-57). New York: Guilford.

Greenberg, L. J., Warwar, S. H., \& Malcolm, W. M. (2008). Differential effects of emotionfocused therapy and psychoeducation in facilitating forgiveness and letting go of emotional injuries. Journal of Counseling Psychology, 55, 185-196. 
Greenberg, L. S., \& Watson, J. (1998). Experiential therapy of depression: Differential effects of client-centered relationship conditions and process experiential interventions. Psychotherapy Research, 8, 210-224.

Greenberg, L.S., \& Webster, M. (1982). Resolving decisional conflict by means of two-chair dialogue: Relating process to outcome. Journal of Counseling Psychology, 29, 468-477.

Hardtke, K. \& Angus, L. (2004). The Narrative Assessment Interview: Assessing Self-change in Psychotherapy. In L. Angus \& J. McLeod, (Eds.), Handbook of Narrative and Psychotherapy: Practice, Theory and Research (pp. 247-262). Thousand Oaks, CA: Sage Publications USA.

Hayes, S., Strosahl, K., \& Wilson, K. (1999). Acceptance and commitment therapy: An experiential approach to behavior change. New York, NY: Guilford Press.

Heatherington, L., Messer, S., Angus, L., Strauman, T., Friedlander, M. \& Kolden, G. (2012). The narrowing of theoretical orientations in clinical psychology doctoral training programs, Clinical Psychology, Science and Practice. 19, 4, 364-374.

Hendricks, M. (2002). Focusing-oriented/Experiential Psychotherapy. In D. Cain \& J. Seeman (Eds.), Humanistic psychotherapies: Handbook of research and practice (pp. 221-251). Washington, D.C.: American Psychological Association.

Hill, C. E. (1978). The development of a system for classifying counselor responses. Journal of Counseling Psychology, 25, 461-468.

Hill, C.E. (Ed.) (2012). Consensual qualitative research: A practical resource for investigating social science phenomena. Washington, D.C.: American Psychological Association.

Hill, C.E., Knox, S., \& Hess, S.A. (2012). Qualitative meta-analysis of consensual qualitative research studies. In C. E. Hill (Ed.), Consensual qualitative research: A practical resource for investigating social science phenomena (pp. 159-171). Washington D.C.: American Psychological Association.

Hill, C.E., Thompson, B.J., \& Williams, E.N. (1997). A guide to conducting consensual qualitative research. The Counseling Psychologist, 25, 517-572.

Holowaty, K. A. M., \& Paivio, S. C. (2012). Characteristics of client-identified helpful events in emotion-focused therapy for child abuse trauma. Psychotherapy Research, 22, 56-66.

HonosWebb, L., Stiles, W. B., Greenberg, L. S. \& Goldman, R. N. (1998). Assimilation analysis of process-experiential psychotherapy: A comparison of two cases. Psychotherapy Research, 8, 264-286.

HonosWebb, L., Surko, M., Stiles, W. B. \& Greenberg, L. S. (1999). Assimilation of voices in psychotherapy: The case of Jan. Journal of Counseling Psychology, 46, 448-460.

Horvath, A., Del Re, A., Fluckiger, C. \& Symonds, D. (2011). Alliance in individual psychotherapy. In J.C. Norcross (Ed.), Psychotherapy Relationships That Work: Evidencebased Responsiveness. (2 ${ }^{\text {nd }}$ Ed., p. 25-69). New York, N.Y.: Oxford University Press.

Horvath, A. \& Greenberg, L. S. (1986). The development of the Working Alliance Inventory. In L. Greenberg \& W. Pinsof (Eds.), The psychotherapeutic process: A research handbook (pp. 529-556). New York: Guilford.

Kagan, N. (1984). Interpersonal Process Recall: Basic methods and recent research. In D. Larson (Ed.), Teaching psychological skills (pp. 229-244). Monterey, California: Brooks Cole.

Kertes, A., Westra, H., Angus, L. \& Marcus, M. (2011). The impact of motivational interviewing on client experiences of cognitive behavioural therapy for generalized anxiety disorder. Cognitive and Behavioral Practice, 18, 55-69. 
Humanistic Psychotherapy Research 1990-2015

Klein, M. H., Mathieu, P. L., Gendlin, E. T., \& Kiesler, D. J. (1969). The Experiencing Scale: A Research Training Manual. Madison, WI: University of Wisconsin Extention Bureau of Audio-visual Instruction.

Klein, M. H., Mathieu-Coughlan, P., \& Kiesler, D. J. (1986). The Experiencing Scales. In L. Greenberg \& W. Pinsof (Eds.), The Psychotherapeutic Process (pp. 21-71). New York: Guilford.

Knox, R. (2008). Clients' experiences of relational depth in person-centred counselling. Counselling \& Psychotherapy Research, 8, 182-188.

Kolden, G. G., Klein, M. H., Wang, C-C., \& Austin, S. B. (2011). Congruence/genuineness. In J. Norcross (Ed.), Psychotherapy relationships that work (2nd ed.) (pp. 187-202). New York: Oxford University Press.

Längle, A., \& Kriz, J. (2012). The renewal of humanism in European psychotherapy: Developments and applications. Psychotherapy, 49, 430-436.

Leahy, R. (2002). A model of emotional schemas. Cognitive and Behavioral Practice, 9, 177190.

Levy, K. \& Anderson, T. (2013). Is clinical psychology doctoral training becoming less intellectually diverse? Clinical Psychology: Science and Practice, 20, 2, 211-220.

Lewin, J., \& Angus, L. (2008). The importance of emotional-reflexive patterns and depth of experiencing for productive experiential therapy: A narrative process analysis. North American Chapter, Society for Psychotherapy Research, Yale, New Haven. CA.

Lewin, J., Angus, L., \& Blagov, P. (2003). Effective patterns of narrative processing for clients and therapists engaged in brief experiential therapy. Paper presented at American Psychological Association Conference, Toronto.

Levitt, H. M., Stanley, C. M., Frank1, Z. \& Raina, K. (2005). An evaluation of outcome measures used in humanistic psychotherapy research: Using thermometers to measure oranges. The Humanistic Psychologist. 33, 2, 113-130.

Macaulay, H. L., Toukmanian, S. G., \& Gordon, K. M. (2007). Attunement as the core of therapist-expressed empathy. Canadian Journal of Counselling, 41, 244-254.

MacLeod, R. \& Elliott, R. (2012). Emotion-focused therapy for social anxiety: A hermeneutic single case efficacy design study of a low-outcome case. Counseling Psychology Review, 27, 7-22.

MacLeod, R., Elliott, R., \& Rodgers, B. (2012). Process-experiential/emotion-focused therapy for social anxiety: A hermeneutic single-case efficacy design study. Psychotherapy Research, 22, 67-81.

Mahrer, A. (1996). The complete guide to experiential psychotherapy. New York: Wiley.

May, R. (1983). The discovery of being: Writings in existential psychology. New York: Norton.

McLeod, J. (2010). Case study research in counselling and psychotherapy. London: Sage.

McLeod, J. (2011). Qualitative research in counselling and psychotherapy. ${ }^{\text {nd }}$ Ed. London: Sage Publications.

McLeod, J. (2013). Qualitative research: Methods and contributions. In Michael J. Lambert (Ed.), Bergin and Garfield's Handbook of Psychotherapy and Behavior Change, $\left(6^{\text {th }}\right.$ Edition)(pp. 49-84). Hoboken, N.J.: John Wiley.

McMullen, E. \& Watson, J. C. (2005). An Examination of Therapist and Client Behaviour in High and Low Alliance Sessions in Cognitive-Behavioural Therapy and Process Experiential Therapy. Psychotherapy: Theory, research, practice, and training, 42, $297-$ 310. 
McNally, S., Timulak, L. \& Greenberg, L. S. (2014). Transforming emotion schemes in emotionfocused therapy: A case study investigation. Person-Centered \& Experiential

Psychotherapies, 13, 128-149.

Mendes, I., Ribeiro, A. P., Angus, L., Greenberg, L. S., Sousa, I., \& Gonçalves, M. M. (2010). Narrative change in emotion-focused therapy: How is change constructed through the lens of the innovative moments coding system? Psychotherapy Research, 20, 692-701.

Mendes, I., Ribeiro, A. P., Angus, L., Greenberg, L. S., Sousa, I., \& Gonçalves, M. M. (2011). Narrative change in emotion-focused psychotherapy: A study on the evolution of reflection and protest innovative moments. Psychotherapy Research, 21, 3, 304-315.

Meneses, C. W. \& Greenberg, L. S. (2011). The Construction of a Model of the Process of Couples' Forgiveness in Emotion-Focused Therapy for Couples. Journal of Marital and Family Therapy, 37, 491-502.

Meyers, S. (2000). Empathic listening: Reports on the experience of being heard. Journal of Humanistic Psychology, 40, 148-173.

Moerman, M. \& McLeod, J. (2006). Person-centered counseling for alcohol-related problems: The client's experience of self in the therapeutic relationship. Person-Centered and Experiential Psychotherapies, 5, 21-35.

Muntigl, P., White, A., Watkins, N., Horvath, A. \& Angus, L. (2013). Active retreating: Personcentred processes to repair disaffiliation in psychotherapy. Journal of Pragmatics, 53, 120.

Neimeyer, R. \& Mahoney, M. (1995). Constructivism in Psychotherapy. Washington, D.C.: American Psychological Association.

Norcross, J.C., \& Wampold, B. E. (2011). Evidence-based therapy relationships: Research conclusions and clinical practices. In J. Norcross (Ed.), Psychotherapy relationships that work (2nd Ed.) (pp. 423-430). New York: Oxford University Press.

Osatuke, K., Glick, M. J., Stiles, W. B., Shapiro, D. A. \& Barkham, M. (2005). Temporal patterns of improvement in client-centred therapy and cognitive-behaviour therapy. Counselling Psychology Quarterly, 18, 95-108.

Paivio, S. C. \& Greenberg, L.S. (1995). Resolving "unfinished business": Efficacy of experiential therapy using empty chair dialogue. Journal of Consulting and Clinical Psychology, 63, 419-425.

Paivio, S.C., Holowaty, K. A. M. \& Hall, I. E. (2004). The influence of therapist adherence and competence on client reprocessing of child abuse memories. Psychotherapy: Theory, Research, Practice, Training, 41, 56-58.

Paivio, S.C. \& Pascual-Leone, A. (2010). Emotion-focused therapy for complex trauma: An Integrative Approach. Washington, DC: American Psychological Association.

Pascual-Leone, A. (2009). Dynamic emotional processing in experiential therapy: Two steps forward, one step back. Journal of Consulting and Clinical Psychology, 77(1), 113-126.

Pascual-Leone, A. \& Greenberg, L. S. (2007). Emotional processing in experiential therapy: Why "the only way out is through". Journal of Consulting and Clinical Psychology, 75, 875-887.

Perls, F. (1976). Gestalt therapy verbatim. New York: Bantam.

Perls, F. S., Hefferline, R. F. \& Goodman, P. (1951). Gestalt Therapy. New York, N.Y.: Julian Press.

Pierson, J., Krug, O., Sharp, J. \& Piwowarski, T. (2015). Cultivating psychotherapist artistry: Model existential-humanistic training programs. In K. Schneider, J. Pierson, \& J. Bugental 
(Eds.) The handbook of humanistic psychology: Theory, research, and practice $\left(2^{\text {nd }}\right.$ Ed.). (pp.631-652).Thousand Oaks: Sage.

Pos, A. E., Greenberg, L. S., Goldman, R. N. \& Korman, L. M. (2003). Emotional processing during experiential treatment of depression. Journal of Consulting and Clinical Psychology, 71, 1007-1016.

Pos, A. E., Greenberg, L. S., \& Warwar, S. (2010). Testing a model of change for experiential treatment of depression. Journal of Consulting and Clinical Psychology, 77, 1055-1066.

Rennie, D. L. (1992). Qualitative analysis of the client's experience of psychotherapy: The unfolding of reflexivity. In S. Toukmanian \& D. Rennie (Eds.), Psychotherapy process research: Paradigmatic and narrative approaches (pp. 211-233). Newbury Park, CA: Sage.

Rennie, D. (1994a). Client's deference in psychotherapy. Journal of Counseling Psychology, 41, 427-437.

Rennie, D. (1994b). Clients' accounts of resistance in counselling: A qualitative analysis. Canadian Journal of Counselling, 28(1), 43-57.

Rhodes, R. H., Hill, C. E., Thompson, B. J., \& Elliott, R. (1994). Client retrospective recall of resolved and unresolved misunderstanding events. Journal of Counseling Psychology, 41, 473-483.

Rice, L. N., \& Saperia, E. P. (1984). Task analysis and the resolution of problematic reactions. In L. N. Rice \& L. S. Greenberg (Eds.), Patterns of change (pp. 29-66). New York: Guilford.

Rodgers, B. (2002). Investigation into the client at the heart of therapy. Counselling and Psychotherapy Research, 2, 185-193.

Rogers, C. R. (1957). The necessary and sufficient conditions of therapeutic personality change. Journal of Consulting Psychology, 21, 95-103.

Rogers, C. R. (1959). A theory of therapy, personality and interpersonal relationships in the client-centred framework. In S. Koch (Ed.), Psychology: A study of science. Vol. III, Formulations of the person in social context. (pp.184-256). New York, N.Y.: McGraw Hill.

Rogers, C. R. (1961). On becoming a person: A therapist's view of psychotherapy. London, United Kingdom: Constable.

Sachse, R. (1992). Differential effects of processing proposals and content references on the explication process of clients with different starting conditions. Psychotherapy Research, 2, 235-251.

Sachse, R., \& Elliott, R. (2002). Process-outcome research on humanistic therapy variables. In D. J. Cain \& J. Seeman (Eds.), Humanistic psychotherapies. Handbook of Research and Practice (pp. 83-116). Washington, DC: APA Books.

Sachse, R., \& Maus, C. (1991). Zielorientiertes Handeln in der Gesprächspsychotherapie. Stuttgart: Kohlhammer.

Sachse, R., \& Takens, R. J. (2004). Klärungsprozesse in der Psychotherapie. Göttingen: Hogrefe.

Sanders, P., \& Hill, A. (2014). Counselling for Depression: A Person-centred and Experiential Approach to Practice. London: Sage.

Schneider, K. J., \& DuPlock, S. (2012). Depth and the marketplace: Psychology's Faustian plight. In L. Barnett and G. Madison (Eds.), Existential therapy: Legacy, vibrancy, and dialogue (pp. 193-208). New York: Routledge. 
Schneider, K. J., \& Krug, O. T. (2010). Existential-humanistic therapy. Washington, D. C.: American Psychological Association.

Schneider, K.J., \& Langle, A. (2012). Introduction: The renewal of humanism in psychotherapy. Psychotherapy, 49, 427-429.

Schneider, K. \& Leitner, L. (2002). Humanistic psychotherapy. Encyclopedia of psychotherapy. Vol. 1, pp. 949-957.

Schneider, K., Pierson, J., \& Bugental, J. (Eds.) (2015). The handbook of humanistic psychology: Theory, research, and practice ( $2^{\text {nd }}$ edition). Thousand Oaks, CA: Sage.

Schnellbacher, J. \& Leijssen, M. (2009). The significance of therapist genuineness from the client's perspective. Journal of Humanistic Psychology, 49, 207-228.

Segal, Z., Williams, J. \& Teasdale, J. (2001). Mindfulness-based cognitive therapy for depression: A new approach to preventing relapse. New York, N. Y.: Guilford Press.

Shahar, B., Carlin, E. R., Engle, D. E., Hegde, J., Szepsenwol, O. and Arkowitz, H. (2012). A pilot investigation of emotion-focused two-chair dialogue intervention for self-criticism. Clinical Psychology \& Psychotherapy.19,6, 496-507.

Sicoli, L. A. \& Hallberg, E. T. (1998). An analysis of client performance in the two-chair method. Canadian Journal of Counselling, 32, 151-162.

Smith, K., Shoemark, A., McLeod, J. \& McLeod, J. (2014). Moving on: A case analysis of process and outcome in person-centred psychotherapy for health anxiety Person-Centered \& Experiential Psychotherapies, 13, 111-127.

Snyder, W. U. (1945). An investigation of the nature of nondirective psychotherapy. Journal of General Psychology, 33, 193-223.

Stephens, S., Elliott, R. \& Macleod, R. (2011). Person-centred therapy with a client experiencing social anxiety difficulties: A hermeneutic single case efficacy design. Counselling \& Psychotherapy Research, 11, 55-66.

Stiles, W. B. (1979). Verbal response modes and psychotherapeutic technique. Psychiatry, 42, 49-62.

Stiles, W. B. (2002). Assimilation of problematic experiences. In J. C. Norcross (Ed.), Psychotherapy relationships that work: Therapist contributions and responsiveness to patients (pp. 357-365). New York: Oxford University Press.

Stiles, W.B., Barkham, M., Mellor-Clark, J., \& Connell, J. (2008). Effectiveness of cognitivebehavioural, person-centred, and psychodynamic therapies as practiced in UK primary care routine practice: Replication in a larger sample. Psychological Medicine, 38, 677-688.

Stiles, W.B., Barkham, M., Twigg, E., Mellor-Clark, J., \& Cooper, M. (2006). Effectiveness of cognitive-behavioural, person-centred and psychodynamic therapies as practised in UK National Health Service settings. Psychological Medicine, 36, 555-566.

Stinckens, N. \& Elliott, R. (2014). Dealing with anxiety in a short-term therapy: Keeping it company or going beyond. Person-Centered \& Experiential Psychotherapies, 13, 94-110.

Stinckens, N., Lietaer, G. \& Leijssen, M. (2002). The inner critic on the move: Analysis of the change process in a case of short-term client-centred/experiential therapy. Counselling \& Psychotherapy Research, 2, 40-54.

Stolorow, R. D. (2011). World, affectivity, trauma: Heidegger and post-Cartesian psychoanalysis. New York: Routledge.

Stolorow, R. D. (2012). The renewal of humanism in psychoanalytic therapy. Psychotherapy, 49, $442-444$. 
Sutherland, O., Peräkylä, A., \& Elliott, R. (in press). Conversation analysis of the two-chair selfsoothing task in emotion-focused therapy. Psychotherapy Research.

Tallman, K. \& Bohart, A. (1999). The client as a common factor : Clients as self-healers. In M. Hubble, B. Duncan \& S. Miller (Eds.), The heart and soul of change: What works in therapy (pp. 91-132). Washington, D. C.: APA Press.

Timulak, L., Belicova, A. \& Miler, M. (2010). Client identified significant events in a successful therapy case: The link between the significant events and outcome. Counselling Psychology Quarterly, 23, 371-386.

Timulak, L. \& Creaner, M. (2010). Qualitative meta-analysis of outcomes of personcentred/experiential therapies. In M. Cooper, J. C. Watson, \& D. Holledampf (Eds.), Person-Centred and Experiential Psychotherapies Work (pp.65-90). Ross-on-Wye: PCCS Books.

Timulak, L., \& Elliott, R. (2003). Empowerment events in process-experiential psychotherapy of depression: A Qualitative Analysis. Psychotherapy Research, 13, 443-460.

Timulak, L., \& McElvaney, J. (July, 2012). Emotion-focused therapy for generalised anxiety disorder. Paper presented at the conference of the World Association for Person-Centered and Experiential Psychotherapy and Counselling, Antwerp, Belgium.

Timulak, L., \& Lietaer, G. (2001). Moments of empowerment: A qualitative analysis of positively experienced episodes in brief person-centred counseling. Counselling \& Psychotherapy Research, 1, 62-73.

Truax, C. B., \& Carkhuff, R. R. (1967). Toward effective counseling and psychotherapy: Training and practice. Chicago: Aldine.

Vontress, C. \& Epp, L. (2015). Existential cross-cultural counseling: The courage to be an existential counselor. In K. Schneider, J. Pierson, \& J. Bugental (Eds.), The handbook of humanistic psychology: Theory, research, and practice ( $2^{\text {nd }}$ edition) (pp. 473-489). Thousand Oaks, CA: Sage.

Wampold, B. E. (2012). Humanism as a common factor in psychotherapy. Psychotherapy, 49, 445-449.

Wampold, B. E. (2008). Existential-integrative psychotherapy comes of age. [Review of the book Existential-integrative psychotherapy: Guideposts to the core of practice]. PsycCritiques 53, Release 6, Article 1.

Warwar, S., \& Greenberg, L. S. (1999). Client emotional arousal scale III-R. Unpublished manual. York Psychotherapy Research Centre, Toronto.

Warwar, S. H. \& Greenberg, L. S. (2000, June). Catharsis is not enough: Changes in emotional processing related to psychotherapy outcome. Paper presented at the International Society for Psychotherapy Research Annual Meeting, Chicago, IL.

Watson, J. C. (2001). Re-visioning empathy. In D. Cain \& J. Seeman (Eds.), Humanistic psychotherapies: Handbook of research and practice (pp. 445-471). Washington: APA.

Watson, J. C. (2007). Facilitating empathy. European Psychotherapy, 7(1), 59-65.

Watson, J. C. (2010). Case formulation in EFT. Journal of Psychotherapy Integration, 20(1), 89100.

Watson, J. C. (2011). The process of growth and transformation: Extending the process model. Person-Centered \& Experiential Psychotherapies, 10(1), 11-27.

Watson, J. C., \& Bedard, D. L. (2006). Clients' emotional processing in psychotherapy: A comparison between cognitive-behavioral and process-experiential therapies. Journal of Consulting and Clinical Psychology, 74, 152-159. 
Watson, J. C. \& Geller, S. (2005). An examination of the relations among empathy, unconditional acceptance, positive regard and congruence in both cognitive-behavioral and process-experiential psychotherapy. Psychotherapy Research, 15, 25-33.

Watson, J.C., Goldman, R.N., \& Greenberg, L.S. (2007). Case-studies in the experiential treatment of depression: A comparison of good and bad outcome. Washington: APA Books.

Watson, J. C., Goldman, R. N., \& Greenberg, L. S. (2011). Humanistic and experiential theories of psychotherapy. In J. C. Norcross, G. R. Vanden Bos \& D. K. Freedheim (Eds.), History of psychotherapy: Continuity and change (2nd Ed., pp.141-172) Washington, D. C.: American Psychological Association.

Watson, J. C., Gordon, L. B., Stermac, L., Kalogerakos, F., \& Steckley, P. (2003). Comparing the effectiveness of process-experiential with cognitive-behavioral psychotherapy in the treatment of depression. Journal of Consulting and Clinical Psychology, 71, 773-781.

Watson, J. C., McMullen, E. J., Prosser, M. C., \& Bedard, D. L. (2011). An examination of the relationships among clients' affect regulation, in-session emotional processing, the working alliance, and outcome. Psychotherapy Research, 21, 86-96.

Watson, J. C. \& Prosser, M. (2007). The relationship of affect regulation to outcome in the treatment of depression. Paper presented to the 22nd Annual Conference of the Society for the Exploration of Psychotherapy Integration, Lisbon, Portugal.

Watson, J., \& Rennie, D. (1994). Qualitative analysis of clients' subjective experience of significant moments during the exploration of problematic reactions. Journal of Counseling Psychology, 41, 500-509.

Watson, J. C., Steckley, P. \& McMullen, E. (2014). The role of empathy in promoting change. Psychotherapy Research, 24, 3, 286-298.

Wertz. F. (2002). Humanistic psychology and the qualitative research tradition. In K.J. Schneider, J. F. Bugental \& J. F. Pierson (Eds.), The handbook of humanistic psychology: Leading edges in theory, research and practice, pp 231-246. Thousand Oaks, C. A.: Sage.

Westra, H. (2012). Motivational interviewing in the treatment of anxiety. New York: Guilford.

Whelton, W. J. \& Greenberg, L. S. (2000). The self as a singular multiplicity: A process experiential perspective. In J. Muran (Ed.), The self in psychotherapy (pp.87-106). Washington, D. C.: American Psychological Association.

Wiggins, S., Elliott, R., \& Cooper, M. (2012). The Prevalence and Characteristics of Relational Depth Events in Psychotherapy. Psychotherapy Research, 22, 139-158.

Wilber, K., Engler, J. \& Brown, D. P. (1986). Transformations of consciousness: Conventional and contemplative perspectives on development. Boston: New Science Library.

Wolfe, B. E. (2008). Cognitive-behavioral innovations of EI practice. In K. Schneider (Ed.), Existential-integrative psychotherapy: Guideposts to the core of practice (pp.204-236). New York: Routledge.

Yalom, I. (1980). Existential psychotherapy. New York: Basic Books. 